\title{
Palladium nanoparticles supported on fluorine-doped tin oxide as an efficient heterogeneous catalyst for Suzuki coupling and 4-nitrophenol reduction
}

\author{
SEK YIN MAK ${ }^{\mathrm{a}}$, KIN HONG LIEW ${ }^{\mathrm{a}, *}$, CHIA CHIA CHUA ${ }^{\mathrm{a}}$, MOHD AMBAR YARMO $^{\mathrm{a}}$, \\ BADRUL H YAHAYA ${ }^{\mathrm{b}}$, WAN ZURINA SAMAD ${ }^{\mathrm{c}}$, MOHD SUZEREN MD JAMIL ${ }^{\mathrm{a}}$ \\ and RAHIMI M YUSOP ${ }^{\mathrm{a}, \mathrm{b}, *}$ \\ ${ }^{a}$ School of Chemical Sciences and Food Technology, Faculty of Science and Technology, \\ Universiti Kebangsaan Malaysia, 43600 UKM Bangi, Selangor Darul Ehsan, Malaysia \\ ${ }^{\mathrm{b}}$ Regenerative Medicine Cluster, Advanced Medical and Dental Institute, Universiti Sains Malaysia, \\ Bertam, 13200 Kepala Batas, Pulau Pinang, Malaysia \\ ${ }^{\mathrm{c}}$ Department of Chemistry, Kulliyyah of Science, International Islamic University Malaysia \\ (IIUM Kuantan Campus), Bandar Indera Mahkota, 25200 Kuantan, Pahang, Malaysia \\ E-mail: edwin85_kh@yahoo.com.sg; rahimi@ukm.edu.my
}

MS received 25 February 2019; revised 16 July 2019; accepted 28 July 2019; published online 9 November 2019

\begin{abstract}
Immobilization of palladium nanoparticles onto the fluorine-doped tin oxide (FTO) as support $\mathrm{Pd} / \mathrm{FTO}$, resulted in a highly active heterogeneous catalyst for Suzuki-Miyaura cross-coupling reactions and 4-nitrophenol reduction. The Pd/FTO catalyst has been synthesized by immobilization of palladium nanoparticles onto FTO via a simple impregnation method. ICP-MS analysis confirmed that there is $0.11 \mathrm{mmol} / \mathrm{g}$ of palladium was loaded successfully on FTO support. The crystallinity, morphologies, compositions and surface properties of Pd/FTO were fully characterized by various techniques. It was further examined for its catalytic activity and robustness in Suzuki coupling reaction with different aryl halides and solvents. The yields obtained from Suzuki coupling reactions were basically over $80 \%$. The prepared catalyst was also tested on mild reaction such as reduction of 4-nitrophenol (4-NP) to 4-aminophenol (4-AP). Pd/FTO catalyst exhibited high catalytic activity towards 4-NP reduction with a rate constant of $1.776 \mathrm{~min}^{-1}$ and turnover frequency (TOF) value of $29.1 \mathrm{hr}^{-1}$. The findings revealed that Pd/FTO also maintained its high stability for five consecutive runs in Suzuki reactions and 4-NP reductions. The catalyst showed excellent catalytic activities by using a small amount of Pd/FTO for the Suzuki coupling reaction and 4-NP reduction.
\end{abstract}

Keywords. Pd/FTO; Suzuki coupling; 4-NP reduction.

\section{Introduction}

Nano-sized palladium $(\mathrm{Pd})$ is a crucial transition metal especially in its function as a catalyst in cross-coupling reactions such as Suzuki-Miyaura, Mizoroki-Heck, Sonogashira, Hiyama, Kumada and Stille reactions. ${ }^{1-6}$ These cross-coupling reactions are utilized in many industrial applications due to the formation of arylaryl, C-C and C-X chemical bonds which are primary steps to synthesize essential intermediates. These remarkable reactions are synthesized products which are important intermediates for pharmaceutical industries, material science, natural products and polymers. $^{7-10}$

The use of heterogeneous Pd catalyst is increased dramatically in both organic and inorganic chemistry research studies as well as the industrial field. ${ }^{1,11}$ This is due to the difficulty of homogeneous Pd catalyst for separation from the reaction medium and makes it almost impossible to be reused after the reaction. ${ }^{11}$ Various types of matrixes have been used in the synthesis of versatile, stable, robust and efficient heterogeneous catalyst without hindering its catalytic sites. $^{6,12}$ The outstanding organometallic-supported

*For correspondence

Electronic supplementary material: The online version of this article (https://doi.org/10.1007/s12039-019-1685-7) contains supplementary material, which is available to authorized users. 
catalyst is highly desirable and becomes a good candidate in the industry due to its economic value, ability in solving product contamination and environmental problems. $^{3}$

Besides, much attention has been paid to the transformation of harmful organic pollutants to useful products. Primary aromatic amine is very important in the manufacture of pharmaceuticals and polymers compounds such as 4-aminophenol (4-AP) and 4-phenylenediamine (4-PDA). ${ }^{13,14}$ In this work, the reduction of 4-nitrophenol (4-NP) will be conducted to test the catalytic activity of $\mathrm{Pd} / \mathrm{FTO}$. The nitroarene reduction has become very important in the research area in transforming the toxic industrial waste, 4-NP, into a useful product, 4-AP. 4-AP can be easily produced via the reduction of 4-NP in mild conditions. 4$\mathrm{AP}$ is an intermediate product for manufacturing drugs in medication such as analgesic and antipyretic, anticorrosion lubricants and hair drying agents. ${ }^{15,16}$

Tin oxide $\left(\mathrm{SnO}_{2}\right)$ is a semiconducting metal oxide material with high energy bandgap $(3.8 \mathrm{eV}) .{ }^{17} \mathrm{SnO}_{2}$ has unique sensing properties which are able to improve its electronic conductivity, IR reflectivity, selectivity and sensitivity through doping of impurities such as copper $(\mathrm{Cu})$ and indium (In). ${ }^{18-20}$ It is also noteworthy that the doping of high electronegative fluorine (F) content onto $\mathrm{SnO}_{2}$ to form FTO displayed remarkable improvements in terms of electronic conductivity and selectivity. ${ }^{19,21}$ Besides, FTO shows higher stability in the aspect of chemical and thermal. $^{22}$ These outstanding properties of FTO are desirable to be applied in gases sensors, transparent conductive coating or glass, and conducting electrode. ${ }^{17,18,21,23-25}$ Recently, Samad and her coworkers were the first to use FTO as a carrier for ruthenium $(\mathrm{Ru})$ nanoparticles and reported its capability in glycerol conversion to methanol. ${ }^{26}$ The article also revealed that Ru/FTO had performed high catalytic activity and selectivity toward hydrogenolysis of glycerol. The effectiveness of the heterogeneous $\mathrm{Ru} / \mathrm{FTO}$ may be contributed by the synergistic effect of fluorine additive and $\mathrm{SnO}_{2}$ as catalyst support. The doping process is able to stabilize the special active sites at the interface between the fluorine additive and $\mathrm{SnO}_{2} \cdot{ }^{27}$ In addition, $\mathrm{SnO}_{2}$ has excellent acidic, basic and redox surface properties which are concerned in catalysis. ${ }^{28}$ Therefore, the amphoteric FTO has a great potential to be a sustainable matrix as a Pd heterogeneous catalyst due to its porous properties, good thermal and chemical stability. ${ }^{26}$ Herein, a new and versatile supported $\mathrm{Pd}$ catalyst is synthesized via immobilization of Pd NPs on FTO as shown in Figure 1 and its catalytic activity is further evaluated in Suzuki coupling reaction and 4-nitrophenol reduction.

\section{Experimental}

\subsection{Reagents}

Palladium acetate $\left(\mathrm{Pd}(\mathrm{OAc})_{2}\right)$, 4-nitrophenol $(\geq 98 \%)$ and sodium borohydride, $\mathrm{NaBH}_{4}(98 \%)$ were purchased from Sigma Aldrich and FTO used as catalyst support was supplied by Keeling \& Walker. Toluene was obtained from DuLAB and hydrazine hydrate and methanol was produced by Merck. Solvents such as diethyl ether, N,N'-dimethylforamide (DMF) and dichloromethane (DCM) were purchased from JT Baker. All chemicals were used as received and without any further purification.

\subsection{Synthesis of Pd/FTO catalyst}

$\mathrm{Pd} / \mathrm{FTO}$ was synthesized according to the following procedure as shown in Figure $1 .{ }^{29} \mathrm{Pd}(\mathrm{OAc})_{2}(0.2 \mathrm{~g}, 10 \% \mathrm{w} / \mathrm{w})$ and FTO $(2.0 \mathrm{~g})$ were added into $25 \mathrm{~mL}$ of toluene solvent in a round-bottom vial. The mixed solution was stirred and heated up to $80{ }^{\circ} \mathrm{C}$ for $10 \mathrm{~min}$. After heating, the mixture was continued to stir at room temperature for $3 \mathrm{~h}$. Subsequently, the resin was filtered and then treated with hydrazine hydrate in methanol $(10 \% \mathrm{v} / \mathrm{v})$ to reduce the $\mathrm{Pd}^{2+}$ to metallic Pd. The resulted resin was then filtered and washed with DCM $(5 \times 20 \mathrm{~mL})$, methanol $(5 \times 20 \mathrm{~mL})$, DMF $(5 \times 20 \mathrm{~mL})$ to remove any impurities from Pd/FTO catalyst. ${ }^{30}$ Afterwards, Pd/FTO was dried to get the final Pd/FTO catalysts.

\subsection{Characterization}

Nitrogen gas adsorption/desorption measurements were carried out at $77 \mathrm{~K}$ using ASAP 2020, Micromeritics system to determine the surface properties of the commercial FTO support and as-prepared Pd/FTO catalyst. The structures and morphologies of the FTO and Pd/FTO were analyzed using a SUPRA 55VP field-emission scanning electron microscopy (FESEM) equipped with an Energy-dispersive X-ray spectroscopy (EDX) and a FEI/Tecnai F-20 X-Twin high-resolution transmission electron microscopy (HRTEM) operated at $200 \mathrm{kV}$ equipped with EDX to identify elements present in sample. X-ray Diffraction (XRD) analysis of the FTO and Pd/FTO were performed with a Bruker D8-Advance diffractometry to characterize their crystalline structures and sizes. The synthesized Pd/FTO nanocatalysts were characterized by using a Perkin Elmer ELAN 9000, USA inductively-coupled plasma mass spectrometry (ICP-MS). The synthesized Pd/FTO were digested by using aqua regia $\left(\mathrm{HNO}_{3}: \mathrm{HCl}\right)$ and diluted with DI water $(<2 \%$ acidity $)$. The solution prepared was then 
sent to ICP-MS analysis to determine the Pd content in FTO. X-ray photoelectron spectroscopy (AXIS Ultra 'DLD', Kratos Analytical) was used to confirm the presence of the palladium metal catalyst. Fourier-transform infrared (FTIR-ATR) spectroscopy analysis was used to determine the functional groups of the materials and it performed in the range of $650 \mathrm{~cm}^{-1}$ to $4000 \mathrm{~cm}^{-1}$ by using a Perkin Elmer Spectrum 400 FT-IR/FT-NIR spectrometry equipped with a Universal ATR. ${ }^{1} \mathrm{H}$ nuclear magnetic resonance (NMR) and ${ }^{13} \mathrm{C}$ NMR spectra of isolated products of Suzuki coupling reactions were recorded on a Bruker Avance 400 III HD spectrometry at $400 \mathrm{MHz}$ and $100 \mathrm{MHz}$, respectively. Reduction of 4-NP was monitored by UV-Vis spectrometry and the spectra were collected with a Shimadzu UV 2450.

\subsection{Catalytic Performance Test on Suzuki Coupling Reaction}

The catalytic performance of Pd/FTO heterogeneous catalyst was evaluated in the Suzuki coupling reaction. Generally, Suzuki coupling reaction was conducted using $1.0 \mathrm{mmol}$ of aryl halide, $1.5 \mathrm{mmol}$ of phenylboronic acid, $3.0 \mathrm{mmol}$ of potassium carbonate $\left(\mathrm{K}_{2} \mathrm{CO}_{3}\right)$, a known amount of Pd/FTO catalyst and $4 \mathrm{~mL}$ of solvent in a $25 \mathrm{~mL}$ round-bottom vial at $80{ }^{\circ} \mathrm{C}$ under atmospheric condition. ${ }^{31}$ For the Suzuki coupling reaction, two types of solvents, DMF and deionized water were used as reaction medium. In addition, $1.0 \mathrm{mmol}$ of tetrabutylammonium bromide (TBAB), which acts as a phase transfer agent, was added to the Suzuki coupling reaction using deionized water as a solvent. ${ }^{32}$ A magnetic stirrer was then added into the vial and sealed by the septum. The sealed mixture was then heated at $80{ }^{\circ} \mathrm{C}$ under magnetic stirring. The reaction was stopped after $15 \mathrm{~h}$ upon completion which was monitored by thin-layer chromatography (TLC).

The mixture was then cooled down to room temperature before centrifuged to separate the Pd/FTO catalyst from the reaction mixture. For the reaction using DMF as the reaction solvent, isolated Pd/FTO was washed with DCM $(5 \mathrm{x}$ $20 \mathrm{~mL})$, methanol (5 x $20 \mathrm{~mL})$, DMF (5 x $20 \mathrm{~mL})$ and dried in the oven for $24 \mathrm{~h}$. The reaction mixture was diluted in
$100 \mathrm{~mL}$ of DCM and subsequently neutralized by $1 \mathrm{M}$ hydrochloric acid $(\mathrm{HCl})$ to $\mathrm{pH}$ 7. The aqueous phase was extracted with DCM (3 x $50 \mathrm{~mL})$. The combined DCM organic solvent was dried over sodium sulfate anhydrous before filtration. The filtrate, DCM organic solvent was then concentrated and dried using rotary evaporator. On the other hand, for the reaction mixture using $\mathrm{H}_{2} \mathrm{O}$ as solvent, the separated catalyst was washed with ethyl acetate and dried in an oven for $24 \mathrm{~h}$. The reaction mixture was extracted with ethyl acetate $(3 \times 50 \mathrm{~mL})$ and $1 \mathrm{M} \mathrm{HCl}$ was added for the purpose of well separation. The organic phase was dried over sodium sulfate anhydrous and followed by filtration. Next, the organic phase was concentrated and dried using rotary evaporator. Purification of product was performed by flash column chromatography on silica gel (hexane: ethyl acetate). Finally, the pure product was collected and its percentage yield was calculated and characterized by NMR spectroscopy and FTIR spectroscopy.

The optimization of the concentration of $\mathrm{Pd} / \mathrm{FTO}$ was carried out with the following conditions: 1-bromo-4-nitrobenzene (204 mg, $1.0 \mathrm{mmol}$ ), phenylboronic acid (182.9 mg, $1.5 \mathrm{mmol}$ ) and $\mathrm{K}_{2} \mathrm{CO}_{3}(414.6 \mathrm{mg}, 3.0 \mathrm{mmol}$ ), different molarity of $\mathrm{Pd} / \mathrm{FTO}$ and $4 \mathrm{~mL}$ of DMF as a solvent. In addition, the reusability of $\mathrm{Pd} / \mathrm{FTO}$ was also examined in DMF and deionized water, respectively.

\subsection{Catalytic test on 4-Nitrophenol reduction}

The catalytic activity of Pd/FTO was further examined in the reduction of 4-NP to 4-AP in a mild condition. The 4-NP reduction is simple and easy to monitor the reaction progress by ultraviolet-visible (UV-Vis) spectroscopy (UV 2450 Shimadzu). The scanning range was set from $250 \mathrm{~nm}$ to $550 \mathrm{~nm}$ with a sampling interval of $2 \mathrm{~nm}$ to monitor the process of the conversion of 4-NP to 4-AP without stirring. Typically, $0.05 \mathrm{mM}$ of 4-NP stock solution was a freshly prepared and large excess of sodium borohydride. $\mathrm{NaBH}_{4}$ was used as a reducing agent. ${ }^{16}$ Firstly, $0.15 \mathrm{mmol} \mathrm{NaBH}_{4}$ was added into $3 \mathrm{~mL}$ of $0.05 \mathrm{mM} 4-\mathrm{NP}$ in a quartz cuvette. Subsequently, $5.0 \mathrm{mg}$ of Pd/FTO was added into the mixture to initiate the hydrogenation of 4-NP. At the end of the reaction, Pd/FTO was separated by centrifugation, washed

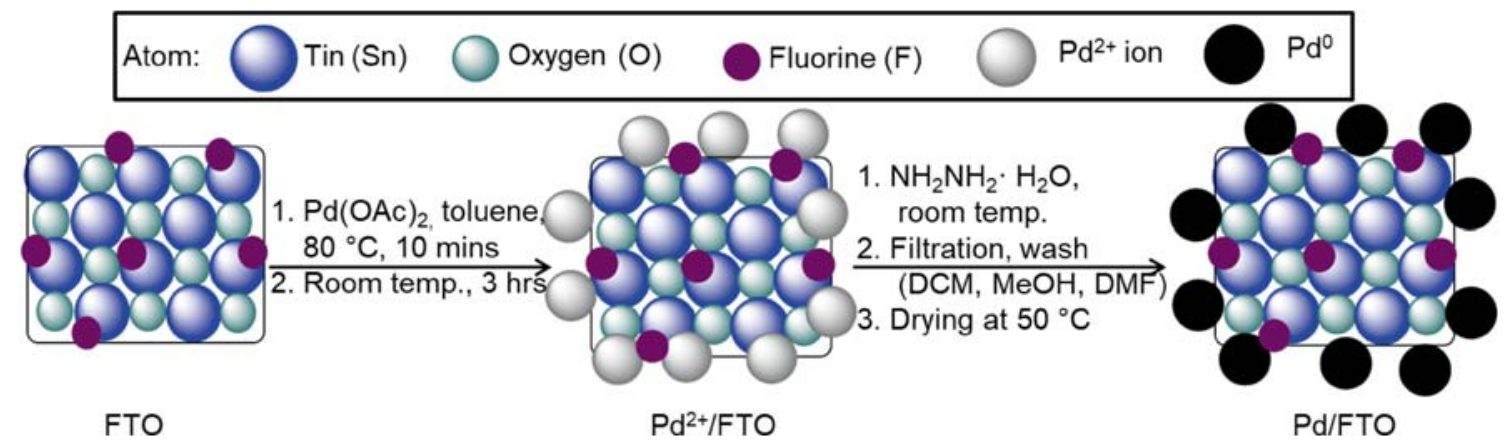

Figure 1. Preparation of Pd/FTO catalyst. 
with deionized (DI) water and acetone, followed by drying in the oven for stability studies. ${ }^{33}$

\section{Results and Discussion}

\subsection{Synthesis and characterization}

ICP analysis was used to determine the content of palladium nanoparticles in the as-prepared catalyst. The ICP results showed that $0.11 \mathrm{mmol} / \mathrm{g}$ of $\mathrm{Pd}$ was loaded onto the FTO support which confirmed the presence of $\mathrm{Pd}$ nanoparticles in the catalyst. On the other hand, $\mathrm{N}_{2}$ adsorption-desorption isotherm results have shown that $\mathrm{Pd} / \mathrm{FTO}$ catalyst has mesoporous with non-uniform pores properties which are explained in Figure S1 and Table S1, Supplementary Information.

The XRD patterns of FTO and Pd/FTO catalysts are compared in Figure 2. Sharp peaks in both diffractograms indicated that FTO and Pd/FTO were presented in crystalline form. Based on Figure 2, the diffraction peaks of FTO are associated with the (110), (101), (200), (111), (210), (211), (220), (002), (310), (112), (301), (202) and (321) planes. All diffraction peaks are matched well with the Bragg reflection and presented in a tetragonal structure of $\mathrm{SnO}_{2}$ which is in agreement with the standard pattern of $\mathrm{SnO}_{2}$ (JCPDS 01-070-4177). ${ }^{34,35}$ The presence of small diffraction peaks at $2 \theta=38.9^{\circ}$ and $42.6^{\circ}$ could be assigned to fluorine. These peak intensities were observed but yet not significant, implying that fluorine elements in FTO are well-dispersed on $\mathrm{SnO}_{2}$ support and most probably are due to the small size and low amount of fluorine. ${ }^{36}$ Moreover, the XRD pattern of Pd/FTO catalyst was found that no significant differences with the XRD pattern of FTO. The absence of Pd diffraction peaks is

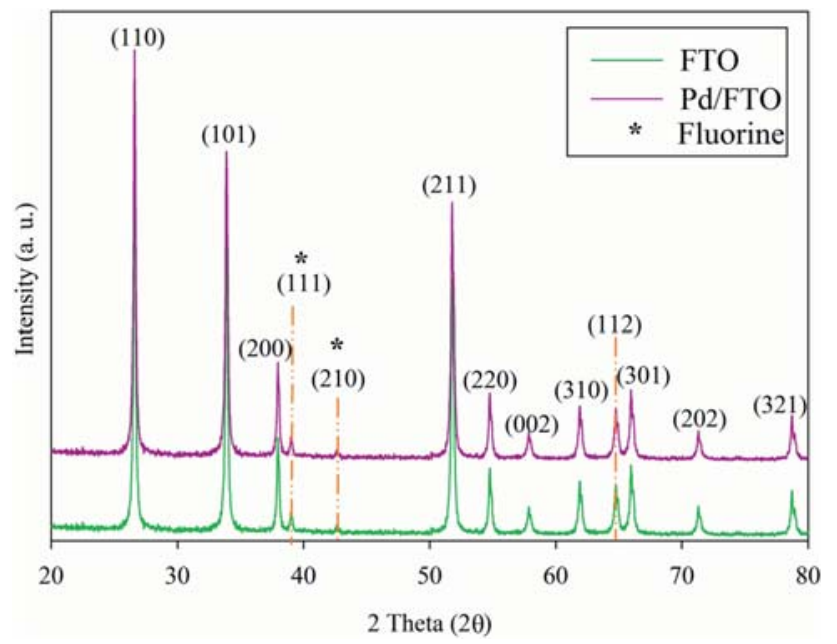

Figure 2. XRD diffractograms of FTO support and $\mathrm{Pd} / \mathrm{FTO}$ catalyst. probably due to the particle sizes of Pd that are too small and low concentration of Pd loaded on FTO $(0.11 \mathrm{mmol} / \mathrm{g} \mathrm{Pd}){ }^{37,38}$ The crystallite sizes of the samples can be calculated by using the Scherrer formula. It was found that the crystallite size of FTO has increased from $36.5 \mathrm{~nm}$ to $40.7 \mathrm{~nm}$ after impregnated with Pd implying the presence of palladium metals which is in agreement with SEM results.

Figure 3 shows the surface morphology and size distribution of FTO support and Pd/FTO by using SEM. Both SEM images showed that FTO consists of a mixture of shapes included tetragonal structures with a diameter range of 20-100 nm and was acknowledged by SEM results from Samad et al. ${ }^{36}$ Based on SEM images of FTO and Pd/FTO in Figure 3, the average size for FTO support was $35.8 \mathrm{~nm}$ while $\mathrm{Pd} / \mathrm{FTO}$ had an average size of $40 \mathrm{~nm}$. The increase in the size of FTO most probably is due to the agglomeration of FTO support during synthesis steps. However, the impregnation of palladium metal catalysts were not destructed the morphology of FTO support. The mapping image of $\mathrm{Pd} / \mathrm{FTO}$ catalyst in Figure 3(c) indicates that the fluorine dopants and $\mathrm{Pd}$ particles were well-dispersed in Pd/FTO while mapping image of FTO is showed in Figure S2(a), Supplementary Information.

The TEM bright-field image in Figure 4(a) shows the catalyst in the range of nanometer which is matching the crystallite size obtained from XRD diffraction pattern using the Scherrer's equation. In Figure 4(a), palladium particles embedded on FTO support with an average diameter of $4 \mathrm{~nm}$. As shown in lattice-resolved HRTEM image (Figure 4(b)), there are two different crystalline fringe patterns. Consistent with XRD results, characteristic lattice fringes of 0.33 $\mathrm{nm}$ spacing confirmed the (110) planes of tetragonal phase $\mathrm{SnO}_{2} \cdot{ }^{39}$ Lattice fringes of $\mathrm{d}=0.23 \mathrm{~nm}$ which agreed well with (111) lattice spacing of facecentred cubic (fcc) of metallic palladium. ${ }^{40,41}$ Figure 4(c) shows the selected area electron diffraction (SAED) pattern of Pd/FTO catalyst. The co-existence of a ring (hexagonal shape) and bright diffraction spots in SAED indicated polycrystalline nature of palladium and $\mathrm{SnO}_{2}$ nanoparticles in the catalyst. $^{42,43}$ This assumption is supported by the FTO analysis done by Zhi and colleagues whereby the SAED pattern of FTO is a single crystalline in nature. ${ }^{44}$ In addition, the presence of palladium element in $\mathrm{Pd} / \mathrm{FTO}$ is detected by HRTEM-EDX spectrum as shown in Figure S3, Supplementary Information.

Figure 5(a) shows the XPS survey scan of the $\mathrm{Pd} / \mathrm{FTO}$ catalyst and revealed that fluorine, oxygen, tin, palladium and carbon were present in the catalyst 

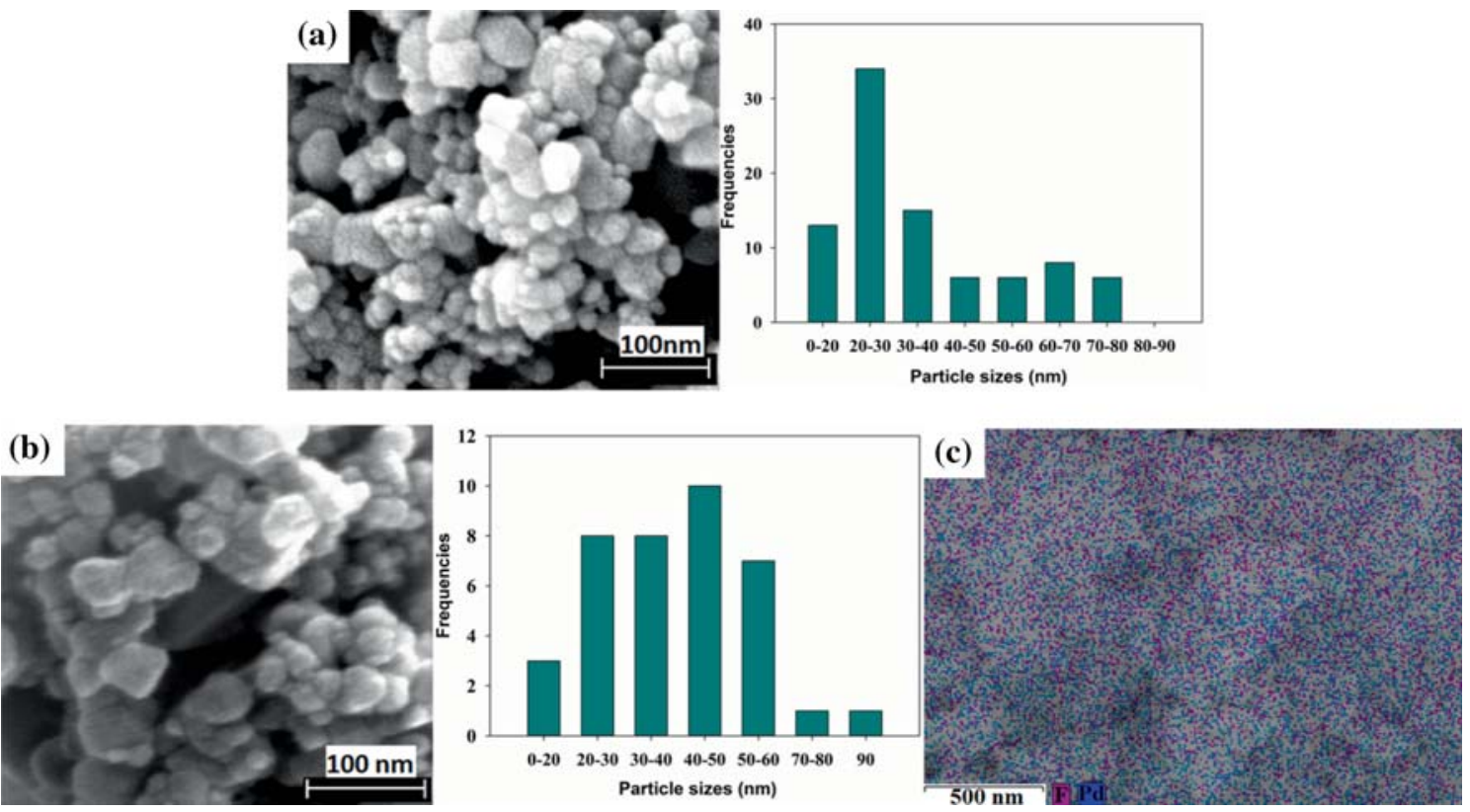

Figure 3. SEM images and size distribution of FTO (a), Pd/FTO catalyst (b) and mapping image of fluorine (purple) and palladium (blue) elements on Pd/FTO (c).

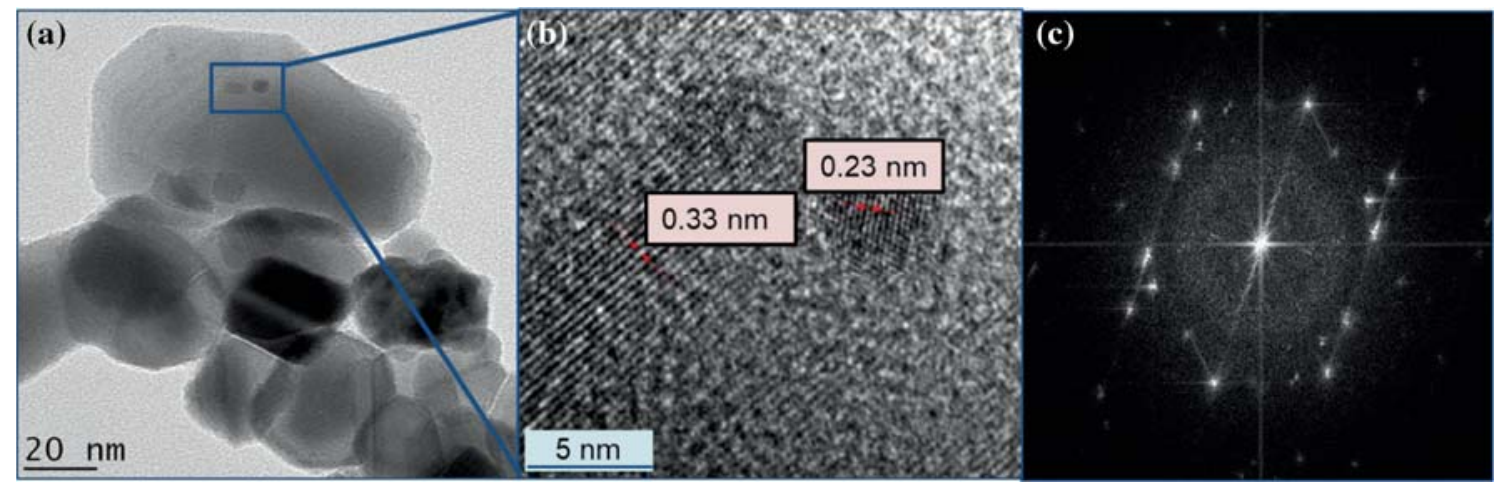

Figure 4. HRTEM image of Pd/FTO in $20 \mathrm{~nm}$ magnification (a), HRTEM image shows lattice fringe in $5 \mathrm{~nm}$ magnification (b) and SAED pattern (c).
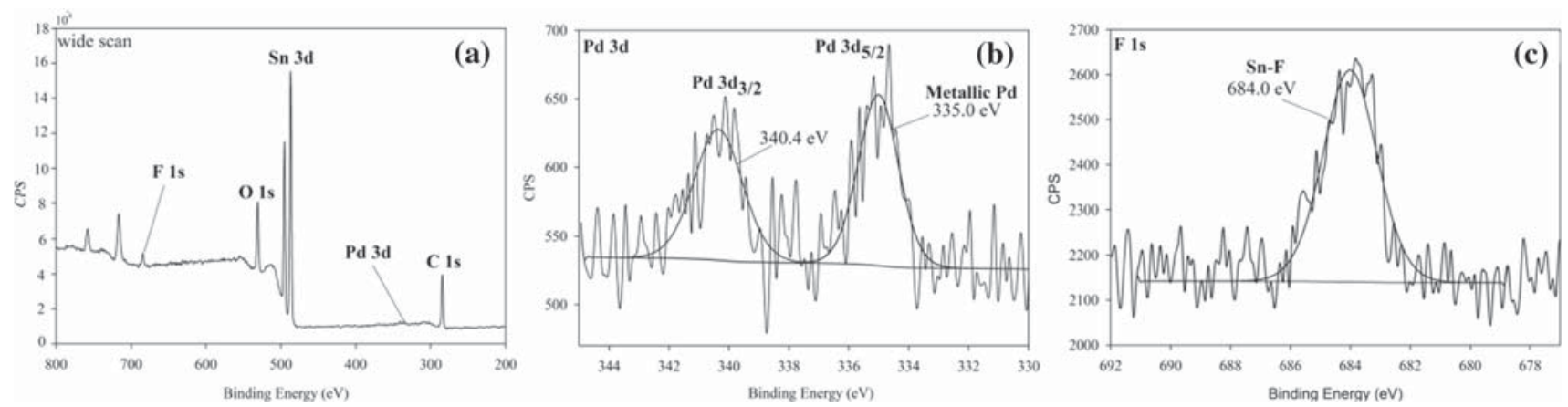

Figure 5. XPS survey scan of spectra of the Pd/FTO (a), high-resolution XPS spectra of Pd 3d (b) and F 1s (c).

which was in agreement with the EDX result in Table 1. XPS spectra are used to identify their chemical states and components. The $\mathrm{C} 1 \mathrm{~s}$ peak was attributed to $\mathrm{C}-\mathrm{C}$ bonds and acted as a reference peak at $284.6 \mathrm{eV}$ for measuring the range of the chemical shifts. ${ }^{45,46}$ XPS spectra of $\mathrm{C} 1 \mathrm{~s}$, Sn $3 \mathrm{~d}$ and $\mathrm{O} 1 \mathrm{~s}$ are showed in Figure S4(a-c), Supplementary Information. On the other hand, the high-resolution XPS scan 
Table 1. Elements present in Pd/FTO determined by XPS.

\begin{tabular}{lc}
\hline Element & Atomic percentage $(\%)$ \\
\hline O 1s & 16.4 \\
Sn 3d & 68.1 \\
Pd 3d & 1.3 \\
C 1s & 11.7 \\
F 1s & 2.5 \\
Total & 100 \\
\hline
\end{tabular}

of Pd 3d (Figure 5(b)) shows doublet peak that splits at $335.0 \mathrm{eV}$ and $340.4 \mathrm{eV}$ that were assigned to metallic Pd $3 d_{5 / 2}$ and Pd $3 d_{3 / 2}$, respectively. ${ }^{47}$ The Pd $3 \mathrm{~d}$ spectrum confirmed that all $\mathrm{Pd}^{2+}$ ions were reduced to metallic Pd. ${ }^{38}$ XPS analysis confirmed the presence of fluorine element in $\mathrm{Pd} / \mathrm{FTO}$ as shown in Figure 5(c). The related peak of $F 1 \mathrm{~s}$ at $684.3 \mathrm{eV}$ was assigned to $\mathrm{Sn}-\mathrm{F}$ complexes formed in the $\mathrm{SnO}_{2}$ framework after the doping process. ${ }^{48,49}$ The weak F 1s peak indicated the presence of fluorine in FTO in a very small amount, which is only $2.5 \%$ in Pd/FTO. ${ }^{48}$ On the other hand, the $1.3 \%$ atomic percentage of palladium exists on the surface of Pd/FTO is detected and is the metal catalyst on surface of FTO that involved in catalysis.

The FTIR transmission spectra of FTO support, $\mathrm{Pd}^{2+} / \mathrm{FTO}$ and Pd/FTO catalyst are shown in Figure 6, confirming the successful impregnation of Pd on FTO support using $\mathrm{Pd}(\mathrm{OAc})_{2}$ as a precursor. The absorption peak at $1740 \mathrm{~cm}^{-1}$ of synthesized $\mathrm{Pd}^{2+} / \mathrm{FTO}$ can be ascribed to the $\mathrm{C}=\mathrm{O}$ stretching of the acetate group from $\mathrm{Pd}(\mathrm{OAc})_{2}$ precursor. ${ }^{50}$ However, the absorption

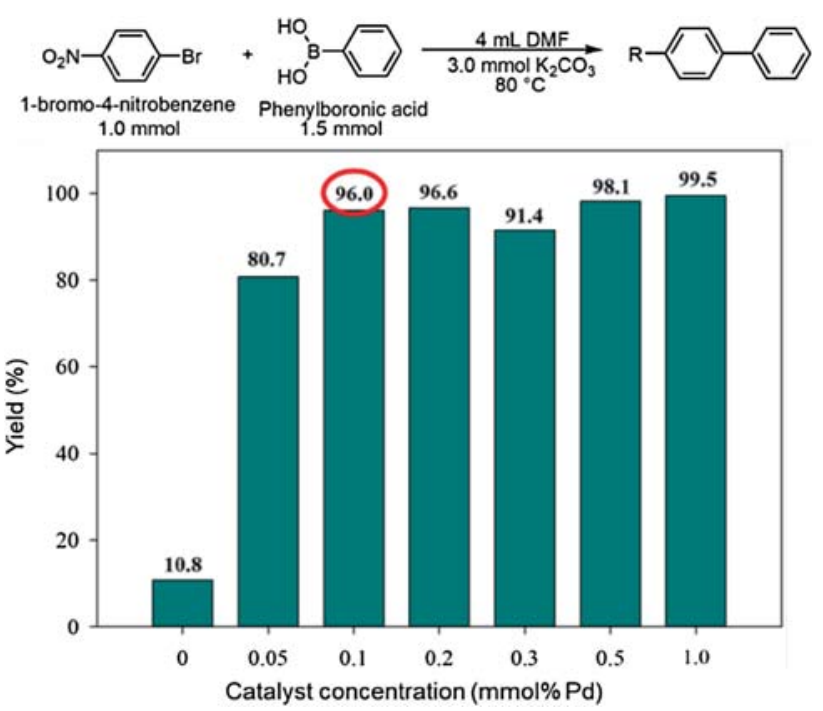

Figure 7. The product yield of Suzuki coupling reaction by using a different concentration of Pd/FTO catalyst.

peak of $\mathrm{C}=\mathrm{O}$ stretching was absent in absorption spectra of FTO and Pd/FTO after reduction of $\mathrm{Pd}^{2+}$ to $\mathrm{Pd}^{0}$. This feature strongly assured that the $\mathrm{Pd}^{2+}$ particles had been reduced to metallic Pd in Pd/FTO.

\subsection{Catalytic performance test}

The catalytic performance of Pd/FTO catalyst was evaluated in the Suzuki coupling reaction by using various concentrations of $\mathrm{Pd} / \mathrm{FTO}$ as shown in Figure 7. The Pd/FTO used in Suzuki coupling reaction of phenylboronic acid with 1-bromo-4-nitrobenzene reactant were varied from $0.05,0.1,0.2,0.3,0.5$,

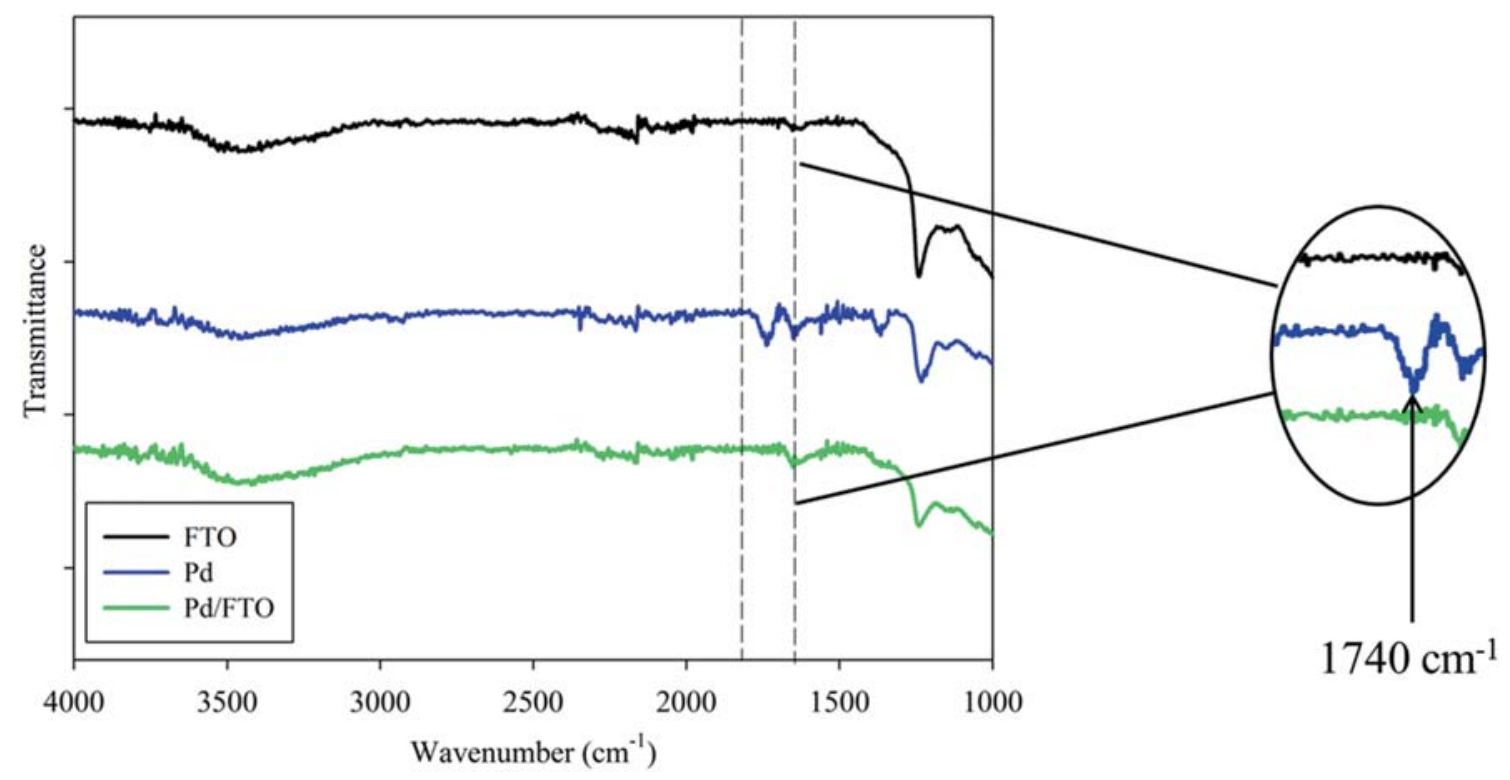

Figure 6. FTIR spectra of FTO (black), $\mathrm{Pd}^{2+} /$ FTO (blue) and Pd/FTO (green). 


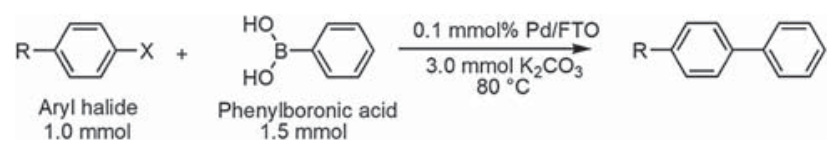

Figure 8. Catalytic test of $\mathrm{Pd} / \mathrm{FTO}$ on Suzuki coupling reaction.

Table 2. Suzuki coupling reaction catalysed by Pd/FTO using different reactants and solvents.

\begin{tabular}{llllc}
\hline & & & \multicolumn{2}{c}{ Isolated yield (\%) } \\
\cline { 4 - 5 } Entry & $\mathrm{X}$ & \multicolumn{1}{c}{$\mathrm{R}$} & $\mathrm{H}_{2} \mathrm{O}^{\mathrm{a}}$ & $\mathrm{DMF}^{\mathrm{b}}$ \\
\hline 1 & $\mathrm{Br}$ & $4-\mathrm{NO}_{2}$ & 85 & 96 \\
2 & $\mathrm{I}$ & $4-\mathrm{NO}_{2}$ & 93.4 & 90 \\
3 & $\mathrm{I}$ & $4-\mathrm{H}$ & 78 & 70 \\
4 & $\mathrm{I}$ & $4-\mathrm{CF}_{3}$ & 90 & 80 \\
5 & $\mathrm{I}$ & $4-\mathrm{CH}_{3}$ & 85 & 76 \\
6 & $\mathrm{I}$ & $4-\mathrm{OCH}_{3}$ & 80 & 78 \\
7 & $\mathrm{Cl}$ & $4-\mathrm{NO}_{2}$ & 25 & 22 \\
8 & $\mathrm{Cl}$ & $4-\mathrm{CH}_{3}$ & 20 & 16 \\
\hline
\end{tabular}

Conditions: Aryl halide $(1.0 \mathrm{mmol})$, phenylboronic acid $(1.5 \mathrm{mmol}), \mathrm{K}_{2} \mathrm{CO}_{3}(3.0 \mathrm{mmol}), \mathrm{Pd} / \mathrm{FTO}(0.1 \mathrm{mmol} \%)$, $80{ }^{\circ} \mathrm{C}, 15 \mathrm{~h}$.

a $4 \mathrm{~mL} \mathrm{H}_{2} \mathrm{O}$, TBAB (1.0 mmol).

b $4 \mathrm{~mL} \mathrm{DMF}$.

Isolated yield is determined by flash column chromatography purification.

1.0 and $1.5 \mathrm{mmol} \%$. The obtained result showed that $\mathrm{Pd} / \mathrm{FTO}$ catalyst exhibited excellent conversion in the Suzuki coupling reaction with low mmol\% of Pd/FTO. From Figure 7, there is an obvious increment of conversion yield from $80.7 \%$ (0.05 $\mathrm{mmol} \%$ ) to $96 \%$ (0.1 mmol\%) and yield more than $90 \%$ of conversion yield when higher mmol\% was used. Optimal reaction condition for Pd/FTO catalyst in Suzuki coupling reaction is $0.1 \mathrm{mmol} \%$ and thus it has been chosen as the best concentration for further studies. The final products obtained were characterized by ${ }^{13} \mathrm{C}$ NMR and ${ }^{1} \mathrm{H}$ NMR in Figure S5-S14, Supplementary Information.

\subsection{Pd/FTO-catalyzed Suzuki coupling reaction}

The as-prepared Pd/FTO was employed as a heterogeneous catalyst in the Suzuki coupling reaction with the conditions shown in Figure 8. The effect of different solvent systems, DMF and $\mathrm{H}_{2} \mathrm{O}$ in the Suzuki coupling reaction catalyzed by $\mathrm{Pd} / \mathrm{FTO}$ was illustrated in Table 2. Results related to the study on the effect of the different solvent systems, DMF and $\mathrm{H}_{2} \mathrm{O}$ on the
Suzuki coupling reaction catalyzed by Pd/FTO was illustrated in Table 2. In Table 2, the optimal solvent of the Suzuki coupling reaction catalyzed by $\mathrm{Pd} / \mathrm{FTO}$ was determined. With the comparable conversion, water is more preferable over DMF in the Suzuki coupling reaction since it is also an effective solvent to obtain high conversion and most importantly, it is a green solvent. ${ }^{51}$ Based on the results showed in Table 2, the product yields of arylbromide and aryliodides are higher than arylchlorides. This is due to the poor reactivity of arylchlorides while both electron-donating $\left(\mathrm{CH}_{3}, \mathrm{OCH}_{3}\right)$ and electron-withdrawing groups $\left(\mathrm{NO}_{2}, \mathrm{CF}_{3}\right)$ on para position of high reactive arylbromides and aryliodides have negligible effect on the reactivity and gives the corresponding biphenyl with excellent yields. ${ }^{52-54}$

\subsection{Recyclability of catalyst on Suzuki coupling reaction}

The reusability of $\mathrm{Pd} / \mathrm{FTO}$ is a significant factor in the heterogeneous system for practical industrial application in Suzuki coupling reaction. To study the reusability of the catalyst, the recovered catalyst was employed in the following cycle under optimum reaction condition. At the same time, the effect of different solvent systems including $\mathrm{H}_{2} \mathrm{O}$ (polar protic solvent) and DMF (polar aprotic solvent) were conducted due to the nature of solvent is playing an

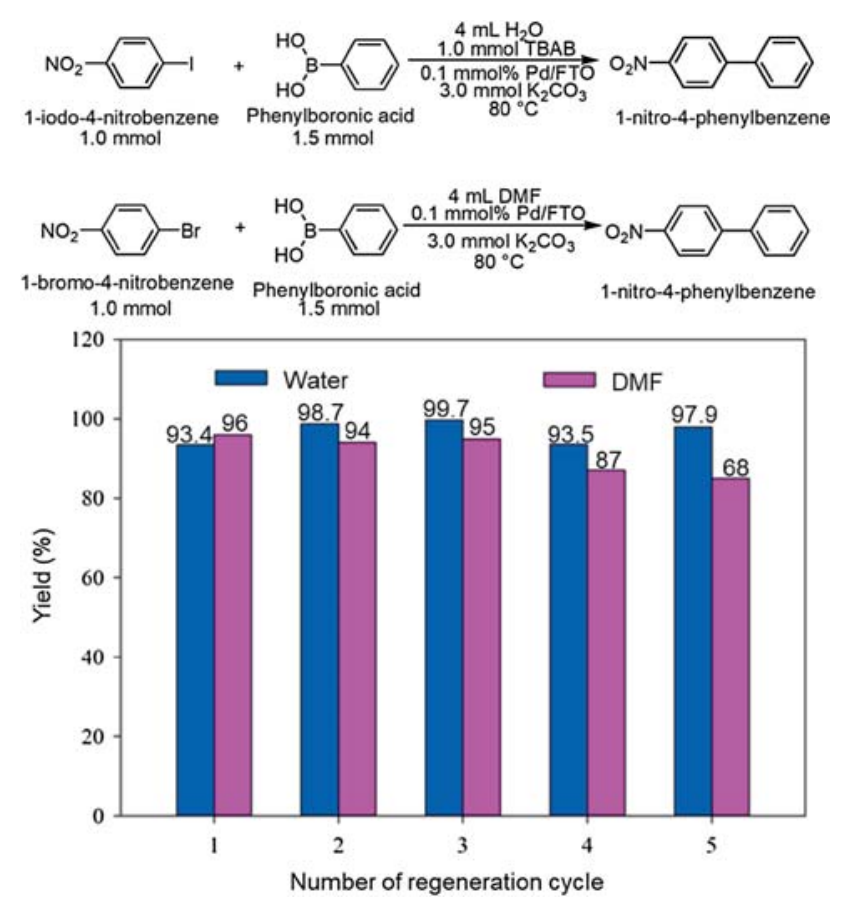

Figure 9. Reusability of prepared Pd/FTO for the Suzuki coupling reaction in $\mathrm{H}_{2} \mathrm{O}$ and DMF. 
Table 3. Comparison of catalyst's efficiency in Suzuki coupling reaction between 4-iodotoluene and phenylboronic acid.

\begin{tabular}{|c|c|c|c|c|c|c|c|}
\hline Catalyst & [Catalyst] & Base & Solvent & Time (hr) & $\begin{array}{c}\text { Temp } \\
\left({ }^{\circ} \mathrm{C}\right)\end{array}$ & $\begin{array}{l}\text { Yield } \\
(\%)\end{array}$ & Reference \\
\hline $\mathrm{Pd} / \mathrm{FTO}$ & $0.1 \mathrm{mmol} \%$ & $\mathrm{~K}_{2} \mathrm{CO}_{3}$ & $\mathrm{H}_{2} \mathrm{O}$ & 15 & 80 & 85.0 & This work \\
\hline $\mathrm{Pd} @ \mathrm{CC}-\mathrm{SO}_{3} \mathrm{H}-\mathrm{NH}_{2}$ & $10 \mathrm{wt} \%$ & $\mathrm{~K}_{2} \mathrm{CO}_{3}$ & $\mathrm{H}_{2} \mathrm{O}$ & 3 & 100 & 75.0 & \\
\hline Pd@PANI & $2 \mathrm{~mol} \%$ & $\mathrm{KOH}$ & $\mathrm{H}_{2} \mathrm{O}$ & 24 & 25 & 85 & 57 \\
\hline Pd-isatin-boehmite & $10 \mathrm{mg}$ & $\mathrm{K}_{2} \mathrm{CO}_{3}$ & PEG-400 & 1.5 & 80 & 93 & 58 \\
\hline $\mathrm{Pd} /$ chitosan-biguanidine & $0.15 \mathrm{~mol} \%$ & $\mathrm{~K}_{2} \mathrm{CO}_{3}$ & EtOH- $\mathrm{H}_{2} \mathrm{O}(1: 1)$ & 0.4 & 40 & 98 & 59 \\
\hline $\begin{array}{l}\text { Pd@ chitosan/starch } \\
\text { composite }\end{array}$ & $0.005 \mathrm{~mol} \%$ & $\mathrm{~K}_{2} \mathrm{CO}_{3}$ & - & $0.1, \mathrm{MW}$ & 50 & 75 & 52 \\
\hline
\end{tabular}

important role in the efficiency of most of the chemical reactions included Suzuki coupling reaction. ${ }^{55,56}$

As shown in Figure 9, the catalytic activity of Pd/ FTO in the Suzuki coupling reaction of aryl halide to biphenyl preserved its activity up to the fifth cycle. The catalytic activity of Pd/FTO in Suzuki coupling reaction in DMF solvent system preserved its activity up to four reaction runs. The yield on the $5^{\text {th }}$ cycle of the reaction was slightly decreased to $85 \%$, which implied that $\mathrm{Pd} /$ FTO could be reused at least four runs with excellent catalytic activity in DMF. Meanwhile, Pd/FTO catalyst demonstrated unchanged high catalytic behaviour (above $90 \%$ yield) in deionized $\mathrm{H}_{2} \mathrm{O}$ after each cycle and can be reused five times without significant decrease in its catalytic activity. However, the fluctuation of the yields obtained in each cycle most probably due to inevitable lost in filtration and purification steps. These findings indicated that the performance of Pd/FTO catalyst is slightly better in $\mathrm{H}_{2} \mathrm{O}$ solvent than in DMF solvent for Suzuki coupling reaction. Nonetheless, the $\mathrm{Pd} / \mathrm{FTO}$ catalyst can be used as an effective heterogeneous catalyst in cross-coupling reaction with excellent catalytic activity and good reusability.

\subsection{Comparison of the effectiveness \\ of the catalyst in the Suzuki coupling reaction}

In order to confirm the efficiency and advantages of $\mathrm{Pd} /$ FTO, the catalytic activity of the present catalyst was compared with previous studies in Suzuki reaction using 4-iodotoluene and phenylboronic acid as shown in Table 3. It is noticeable that the present catalyst was potentially performed to yield 4-methylbiphenyl, relatively in the presence of a low concentration of catalyst, moderate temperature and water as a green solvent.

\subsection{Reduction of 4-NP to 4-AP}

The hydrogenation of 4-NP to 4-AP can be tracked by following the changes of absorbance peaks in UV-Vis spectra at $400 \mathrm{~nm}$ and $300 \mathrm{~nm}$ as shown in Figure 10(a). ${ }^{60}$ Peak at $400 \mathrm{~nm}$ appeared immediately upon the addition of $\mathrm{NaBH}_{4}$ due to the presence of 4-nitrophenolate ion. After the addition of Pd/FTO catalyst, the peak at $400 \mathrm{~nm}$ experienced hypochromic effect successively within 110 seconds, whereas a new peak was presented at $300 \mathrm{~nm}$ corresponding to the 4-AP product. $^{61}$

The mechanism of 4-nitrophenol reduction on $\mathrm{Pd} /$ FTO catalyst based on Langmuir-Hinshelwood model is proposed schematically in Figure S15, Supplementary Information. ${ }^{62-64}$ On the surface of Pd/FTO catalyst, adsorption of hydrogen (sources from sodium borohydride) and 4-nitrophenol reactants occurred prior to reduction of the nitro group. Followed by the series of electron transfers, the reduction occurred to form the corresponding aminobenzene and finally desorbed from the metal surface.

Kinetic measurements of Pd/FTO were performed as shown in Figure 10(b). Notably, the reduction started after $10 \mathrm{~s}$ upon addition of the Pd/FTO. There is an induction period for the first $10 \mathrm{~s}$ and followed by a linear behaviour are observed in the pseudofirst-order plot. The induction period occurred because time is required for the catalyst to diffuse from the surface into the reaction medium. This action is essential to allow reactant and reducing species to be adsorbed onto the nanocatalyst surface. ${ }^{65}$ In addition, 4-NP reduction is not feasible when FTO support is added to the reaction medium. This observation implies that the FTO support without Pd catalyst impregnated has low or negligible catalytic activity towards the reaction (data not shown).

The rate of the reaction is determined by the slope of linear In $\left(A_{t} / A_{0}\right)$ versus reaction time based on the rate equation In $\left(\mathrm{A} / \mathrm{A}_{0}\right)=-k \mathrm{t} .{ }^{66}$ As shown in Figure (b), the calculated value of $k$ was $1.776 \mathrm{~min}^{-1}$ with good linear regression of $\mathrm{R}^{2}$ of 0.967 . To further evaluate the catalytic performance of the $\mathrm{Pd} / \mathrm{FTO}$, the 
(a)

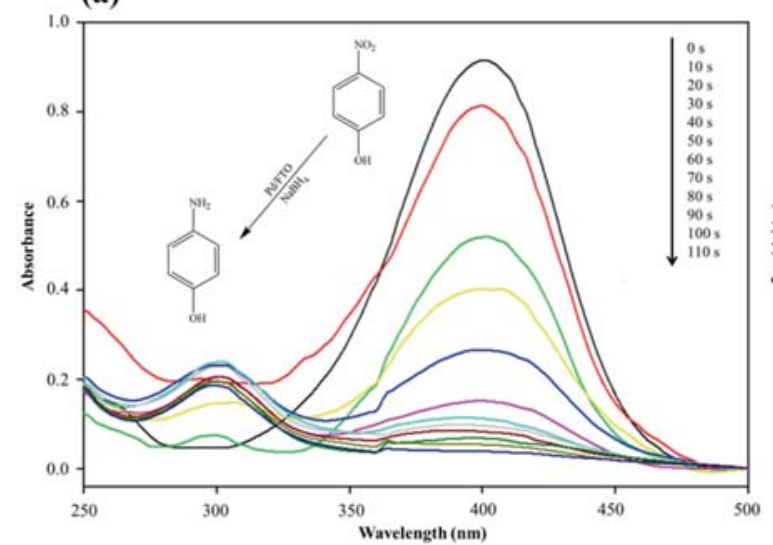

(c)

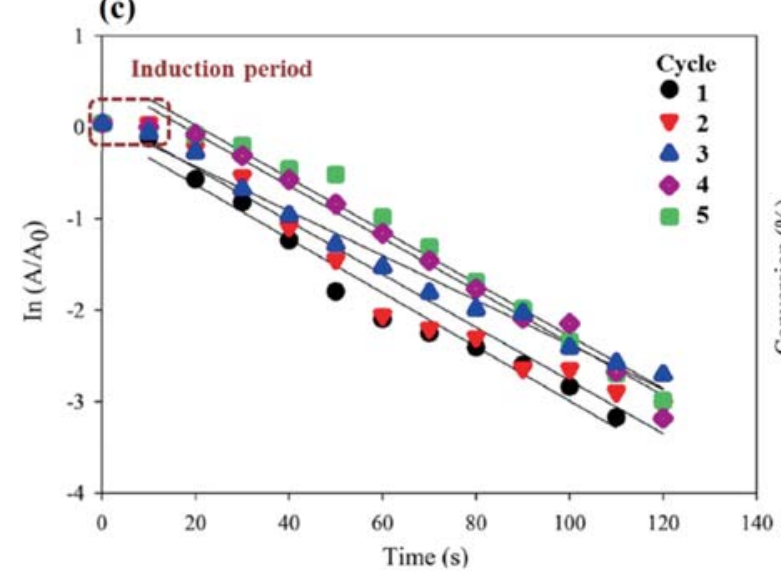

(b)

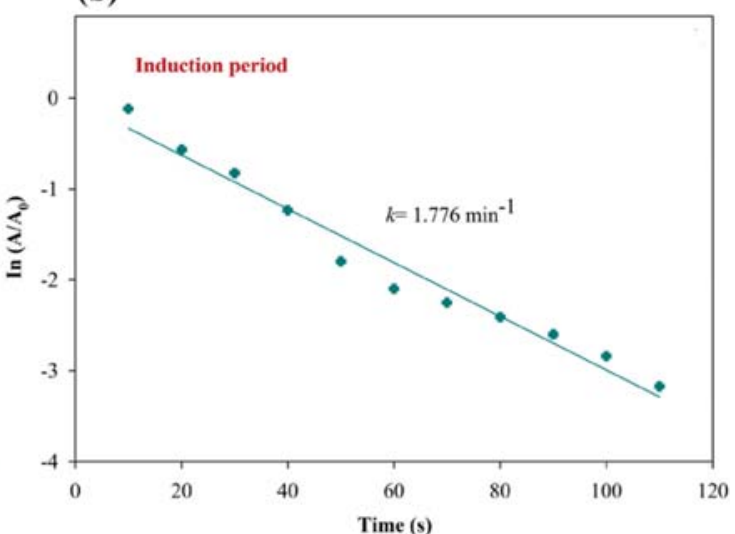

(d)

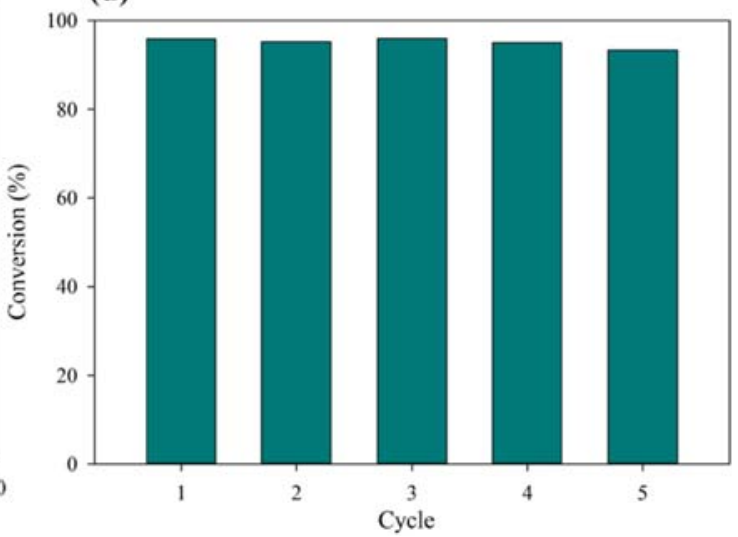

Figure 10. Kinetic study of the reduction of 4-NP to 4-AP using $\mathrm{NaBH}_{4}$ over the prepared Pd/FTO catalyst (a) Plot of In (A/A $\left.\mathrm{A}_{0}\right)$ at $400 \mathrm{~nm}$ as a function of reaction time for the first run of Pd/FTO in the 4-NP reduction (b) Plot of $\operatorname{In}\left(\mathrm{A} / \mathrm{A}_{0}\right)$ at $400 \mathrm{~nm}$ as a function of reaction time at different runs (c) Graphical illustration of the catalytic stability of Pd/FTO in the 4-NP reduction (d).

turnover frequency (TOF) was calculated to be 29.1 $\mathrm{hr}^{-1}$ using the equation below ${ }^{33}$ :

$\mathrm{TOF}=k \frac{n_{0 \text { reactant }}}{n_{P d}}$

The recyclability of the catalyst was also tested on 4-NP reduction. The reaction rates for each cycle are shown in Figure 10(c). Pd/FTO was ably reused up to five consecutive runs with the same reaction conditions and each cycle was maintained above $90 \%$ conversion as illustrated in Figure 10(d). In conclusion, the prepared $\mathrm{Pd} / \mathrm{FTO}$ showed excellent catalytic ability and reusability for the reduction of 4-NP to 4-AP.

\subsection{Comparison of the effect of the catalyst in 4- nitrophenol reduction}

The catalytic activity of the present catalyst in 4-nitrophenol reduction has been compared with other

Table 4. Comparison of the activity of Pd/FTO with other catalysts used in 4-nitrophenol reduction.

\begin{tabular}{|c|c|c|c|c|c|c|c|}
\hline Catalyst & $\begin{array}{c}\text { Amount of catalyst } \\
\text { used }(\mathrm{mg})\end{array}$ & $\begin{array}{c}{[4-\mathrm{NP}]} \\
(\mathrm{mM})\end{array}$ & $\begin{array}{l}{\left[\mathrm{NaBH}_{4}\right]} \\
(\mathrm{M})\end{array}$ & $\begin{array}{l}\text { Reaction } \\
\text { time (s) }\end{array}$ & $\begin{array}{l}\text { rate constant, } \\
\qquad k\left(\min ^{-1}\right)\end{array}$ & $\begin{array}{c}\text { TOF } \\
\left(\mathrm{hr}^{-1}\right)\end{array}$ & Reference \\
\hline Pd/FTO & 5.0 & 0.05 & 0.15 & 110 & 1.776 & 29.1 & \multirow{2}{*}{ This work } \\
\hline CuNiOS-0.6 & 10 & 0.15 & 0.1 & 90 & 4.2 & - & \\
\hline $\begin{array}{l}\text { Pt@Ag core- } \\
\text { shell }\end{array}$ & 0.05 & 0.10 & 0.0001 & 480 & 0.355 & 5.28 & 67 \\
\hline Pd@rGO & 0.25 & 1.0 & 1.00 & 130 & - & - & 68 \\
\hline $\begin{array}{c}\mathrm{Au} / \mathrm{CeO}_{2} @ \\
\mathrm{~g}-\mathrm{C}_{3} \mathrm{~N}_{4}\end{array}$ & 1.0 & 0.12 & 0.04 & 40 & 6.38 & - & 69 \\
\hline Ni@N-doped & 0.32 & 3.0 & 0.02 & 270 & 0.761 & - & 70 \\
\hline
\end{tabular}


catalysts as shown in Table 4. In 4-nitrophenol reduction, the present catalyst is comparable in terms of amount of catalyst used, reaction time, rate constant and TOF.

\section{Conclusions}

The present study has proved that the nano-sized FTO is a promising catalyst support in catalysis. The efficiency of the Pd/FTO was examined in the Suzuki coupling reaction and 4-NP reduction using UV-Vis spectroscopy. Pd/FTO was performed excellently in both harsh and milder reaction conditions. Moreover, this promising recoverable catalyst exhibited high catalytic performance and recyclability in Suzuki coupling reaction and 4-nitrophenol reduction over low concentration of catalyst.

\section{Supplementary Information (SI)}

Table S1 and Figures S1-S15 are available at www.ias.ac. in/chemsci.

\section{Acknowledgements}

Financial assistance from Universiti Kebangsaan Malaysia (UKM) for a research grant (GUP-2016-063) and MalaysiaThailand Joint Authority (ST-2018-005) are acknowledged. The authors are gratefully acknowledged to Center for Research and Instrumentation (CRIM) UKM for providing the facilities for the analysis work. Lastly, we are grateful to our lab associates, colleagues and staffs for their knowledge supports and assists during this research.

\section{References}

1. Fareghi-Alamdari R, Golestanzadeh $\mathrm{M}$ and Bagheri $\mathrm{O}$ 2017 An efficient and recoverable palladium organocatalyst for Suzuki reaction in aqueous media Appl. Organomet. Chem. 31 e3698

2. Hekmati M, Bonyasi F, Javaheri $\mathrm{H}$ and Hemmati $\mathrm{S}$ 2017 Green synthesis of palladium nanoparticles using Hibiscus sabdariffa L. flower extract: Heterogeneous and reusable nanocatalyst in Suzuki coupling reactions Appl. Organomet. Chem. 31 e 3757

3. Hajipour A R and Tavangar-Rizi Z 2017 Palladium nanoparticles immobilized on magnetic methioninefunctionalized chitosan: A versatile catalyst for Suzuki and copper-free Sonogashira reactions of aryl halides at room temperature in water as only solvent Appl. Organomet. Chem. 31 e3701

4. Du Q and Li Y 2012 Application of an air-and-moisture-stable diphenylphosphinite cellulose-supported nanopalladium catalyst for a Heck reaction Res. Chem. Intermed. 381807
5. Geyer F L, Brosius V and Bunz U H 2015 2-bromotetraazapentacene and Its functionalization by $\mathrm{Pd}$ (0)-Chemistry J. Org. Chem. 8012166

6. Shah D and Kaur H 2016 Supported palladium nanoparticles: A general sustainable catalyst for microwave enhanced carbon-carbon coupling reactions J. Mol. Catal. A: Chem. 424171

7. Zhou P, Wang H, Yang J, Tang J, Sun D and Tang W 2012 Bacteria cellulose nanofibers supported palla$\operatorname{dium}(0)$ nanocomposite and its catalysis evaluation in Heck reaction Ind. Eng. Chem. Res. 515743

8. Xing G 2016 Palladium immobilized on aminated polyacrylonitrile nanofiber as an efficient heterogeneous catalyst for Heck reaction Fibers Polym. 17194

9. Lu G, Franzen R, Yu X J and Xu Y J 2006 Synthesis of Flurbiprofen via Suzuki reaction catalyzed by palladium charcoal in water Chin. Chem. Lett. 17461

10. Albani D, Vilé G, Mitchell S, Witte P T, AlmoraBarrios N, Verel R, López N and Pérez-Ramírez J 2016 Ligand ordering determines the catalytic response of hybrid palladium nanoparticles in hydrogenation Catal. Sci. Technol. 61621

11. Monguchi Y, Wakayama F, Ueda S, Ito R, Takada H, Inoue H, Nakamura A, Sawama Y and Sajiki H 2017 Amphipathic monolith-supported palladium catalysts for chemoselective hydrogenation and cross-coupling reactions $R S C A d v .71833$

12. Liu C, Li M, Wang J, Zhou X, Guo Q, Yan J and Li Y 2016 Plasma methods for preparing green catalysts: Current status and perspective Chin. J. Catal. 37340

13. Viswanathan P and Ramaraj R 2018 Gold nanodots self-assembled polyelectrolyte film as reusable catalyst for reduction of nitroaromatics J. Chem. Sci. 1304

14. Farooqi Z H, Khalid R, Begum R, Farooq U, Wu Q, Wu W, Ajmal M, Irfan A and Naseem K 2019 Facile synthesis of silver nanoparticles in a crosslinked polymeric system by in situ reduction method for catalytic reduction of 4-nitroaniline Environ. Technol. 40 2027

15. Deraedt C, Salmon L and Astruc D 2014 "Click" dendrimer-stabilized palladium nanoparticles as a green catalyst down to parts per million for efficient C-C cross-coupling reactions and reduction of 4-nitrophenol Adv. Synth. Catal. 3562525

16. Nandanwar S U and Chakraborty M 2012 Synthesis of colloidal $\mathrm{CuO} / \gamma-\mathrm{Al}_{2} \mathrm{O}_{3}$ by microemulsion and its catalytic reduction of aromatic nitro compounds Chin. J. Catal. 331532

17. Juttukonda V, Paddock R L, Raymond J E, Denomme D, Richardson A E, Slusher L E and Fahlman B D 2006 Facile synthesis of tin oxide nanoparticles stabilized by dendritic polymers J. Am. Chem. Soc. 128420

18. Zhang G and Liu M 2000 Effect of particle size and dopant on properties of $\mathrm{SnO}_{2}$-based gas sensors Sens. Actuat. B 69144

19. Boegeat D, Jousseaume B, Toupance T, Campet G and Fournes L 2000 The first mixed-valence fluorotin alkoxides: new sol- gel precursors of fluorine-doped tin oxide materials Inorg. Chem. 393924

20. Vannucci A K, Alibabaei L, Losego M D, Concepcion J J, Kalanyan B, Parsons G N and Meyer T J 2013 Crossing the divide between homogeneous and 
heterogeneous catalysis in water oxidation PNAS USA 11020918

21. Han C-H, Han S-D, Gwak J and Khatkar S 2007 Synthesis of indium tin oxide (ITO) and fluorine-doped tin oxide (FTO) nano-powder by sol-gel combustion hybrid method Mater. Lett. 611701

22. Tran Q-P, Fang J-S and Chin T-S 2015 Properties of fluorine-doped $\mathrm{SnO}_{2}$ thin films by a green sol-gel method Mater. Sci. Semicond. Process. 40664

23. Zhang J and Gao L 2004 Synthesis and characterization of nanocrystalline tin oxide by sol-gel method J. Solid State Chem. 1771425

24. Murakami T N and Grätzel M 2008 Counter electrodes for DSC: application of functional materials as catalysts Inorg. Chim. Acta 361572

25. Kent C A, Concepcion J J, Dares C J, Torelli D A, Rieth A J, Miller A S, Hoertz P G and Meyer T J 2013 Water oxidation and oxygen monitoring by cobaltmodified fluorine-doped tin oxide electrodes $J$. Am. Chem. Soc. 1358432

26. Samad W Z, Isahak W N R W, Liew K H, Nordin N, Yarmo M A and Yusop M R 2014 Ru/FTO: Heterogeneous catalyst for glycerol hydrogenolysis AIP Conf. Proc. pp 269-274

27. Batzill M and Diebold U 2005 The surface and materials science of tin oxide Prog. Surf. Sci. 7947

28. Varala R, Narayana V, Kulakarni S R, Khan M, Alwarthan A and Adil S F 2016 Sulfated tin oxide (STO)-Structural properties and application in catalysis: A review Arab. J. Chem. 9550

29. Liew K H, Samad W Z, Nordin N, Loh P L, Juan J C, Yarmo M A, Yahaya B H and Yusop R M 2015 Preparation and characterization of HypoGel-supported Pd nanocatalysts for Suzuki reaction under mild conditions Chin. J. Catal. 36771

30. Cho J K, Najman R, Dean T W, Ichihara O, Muller C and Bradley M 2006 Captured and cross-linked palladium nanoparticles J. Am. Chem. Soc. 1286276

31. Najman R, Cho J K, Coffey A F, Davies J W and Bradley M 2007 Entangled palladium nanoparticles in resin plugs Chem. Commun. 5031

32. Liew K H, Loh P L, Juan J C, Yarmo M A and Yusop R M 2014 QuadraPure-supported palladium nanocatalysts for microwave-promoted suzuki cross-coupling reaction under aerobic condition Sci. World J. 20147

33. Liew K H, Rocha M, Pereira C, Pires A L, Pereira A M, Yarmo M A, Juan J C, Yusop R M, Peixoto A F and Freire C 2017 Highly active ruthenium supported on magnetically recyclable chitosan-based nanocatalyst for nitroarenes reduction ChemCatChem 93930

34. Kumar V, Singh K, Singh K, Kumari S, Kumar A and Thakur A 2016 Effect of solvent on the synthesis of $\mathrm{SnO}_{2}$ nanoparticles AIP Conf. Proc. 1728020532

35. Alaf M, Guler M O, Gultekin D, Uysal M, Alp A and Akbulut H 2008 Effect of oxygen partial pressure on the microstructural and physical properties on nanocrystalline tin oxide films grown by plasma oxidation after thermal deposition from pure Sn targets Vacuum 83292

36. Samad W Z, Goto M, Kanda H, Nordin N, Liew K H, Yarmo M A and Yusop M R 2017 Fluorine-doped tin oxide catalyst for glycerol conversion to methanol in sub-critical water J. Supercrit. Fluids 120366

37. Khan Z, Dummer N F and Edwards J K 2018 Silverpalladium catalysts for the direct synthesis of hydrogen peroxide Philos. Trans. $R$ Soc. A 376

38. Xue N, Yu R-J, Yuan C-Z, Xie X, Jiang Y-F, Zhou H-Y, Cheang T-Y and Xu A-W 2017 In situ redox deposition of palladium nanoparticles on oxygen-deficient tungsten oxide as efficient hydrogenation catalysts $R S C A d v .72351$

39. Guan X, Luo P, Li X, Yu Y, Chen D and Zhang L 2018 One-step facile synthesis of hierarchically porous nitrogen-doped $\mathrm{Sno}_{2}$ nanoparticles with ultrahigh surface area for enhanced lithium storage performance Int. J. Electrochem. Sci. 135667

40. Zhang H, Sun J, Dagle V L, Halevi B, Datye A K and Wang Y 2014 Influence of $\mathrm{ZnO}$ facets on $\mathrm{Pd} / \mathrm{ZnO}$ catalysts for methanol steam reforming ACS Catal. 4 2379

41. Metin Ö, Sun X and Sun S 2013 Monodisperse goldpalladium alloy nanoparticles and their compositioncontrolled catalysis in formic acid dehydrogenation under mild conditions Nanoscale 5910

42. Sengupta D, Saha J, De G and Basu B $2014 \mathrm{Pd} / \mathrm{Cu}$ bimetallic nanoparticles embedded in macroporous ion-exchange resins: an excellent heterogeneous catalyst for the Sonogashira reaction J. Mater. Chem. A 2 3986

43. Tammina S K, Mandal B K, Ranjan S and Dasgupta N 2017 Cytotoxicity study of Piper nigrum seed mediated synthesized $\mathrm{SnO}_{2}$ nanoparticles towards colorectal (HCT116) and lung cancer (A549) cell lines J. Photochem. Photobiol. B 166158

44. Zhi X, Zhao G, Zhu T and Li Y 2008 The morphological, optical and electrical properties of $\mathrm{SnO}_{2}$ : F thin films prepared by spray pyrolysis Surf. Interface Anal. 4067

45. Tressaud A, Labrugère C, Durand E, Brigouleix C and Andriessen H 2009 Switchable hydrophobic-hydrophilic layer obtained onto porous alumina by plasma-enhanced fluorination Sci. China Ser. E: Technol. Sci. 52104

46. Babar A, Shinde S, Moholkar A, Bhosale C, Kim J and Rajpure K 2011 Physical properties of sprayed antimony doped tin oxide thin films: The role of thickness J. Semicond. 32053001

47. Elazab H A, Moussa S, Siamaki A R, Gupton B F and El-Shall M S 2017 The Effect of graphene on catalytic performance of palladium nanoparticles decorated with $\mathrm{Fe}_{3} \mathrm{O}_{4}, \mathrm{Co}_{3} \mathrm{O}_{4}$, and $\mathrm{Ni}(\mathrm{OH})_{2}$ : Potential efficient catalysts used for suzuki cross-coupling Catal. Lett. 147 1510

48. Martinez A, Huerta L, de León J O-R, Acosta D, Malik $\mathrm{O}$ and Aguilar M 2006 Physicochemical characteristics of fluorine doped tin oxide films J. Phys. D 395091

49. Noor N and Parkin I P 2013 Enhanced transparentconducting fluorine-doped tin oxide films formed by aerosol-assisted chemical vapour deposition J. Mater. Chem. C 1984

50. Yu J, Wang C, Xiang L, Xu Y and Pan Y 2018 Enhanced $\mathrm{C}_{3} \mathrm{H}_{6} / \mathrm{C}_{3} \mathrm{H}_{8}$ separation performance in poly 
(vinyl acetate) membrane blended with ZIF-8 nanocrystals Chem. Eng. Sci. 1791

51. Rathod P V and Jadhav V H 2017 Palladium incorporated on carbonaceous catalyst for Suzuki coupling reaction in water Tetrahedron Lett. 581006

52. Baran T, Yılmaz Baran N and Menteş A 2018 Sustainable chitosan/starch composite material for stabilization of palladium nanoparticles: Synthesis, characterization and investigation of catalytic behaviour of Pd@chitosan/starch nanocomposite in SuzukiMiyaura reaction Appl. Organomet. Chem. 32 e4075

53. Han D, Zhang Z, Bao Z, Xing H and Ren Q 2018 Pd-Ni nanoparticles supported on titanium oxide as effective catalysts for Suzuki-Miyaura coupling reactions Front. Chem. Sci. Eng. 1224

54. Dadras A, Naimi-Jamal M R, Moghaddam F M and Ayati S E 2018 Green and selective oxidation of alcohols by immobilized $\mathrm{Pd}$ onto triazole functionalized $\mathrm{Fe}_{3} \mathrm{O}_{4}$ magnetic nanoparticles J. Chem. Sci. 130162

55. Pourkhosravani M, Dehghanpour $\mathrm{S}$ and Farzaneh $\mathrm{F}$ 2016 Palladium nanoparticles supported on zirconium metal organic framework as an efficient heterogeneous catalyst for the Suzuki-Miyaura coupling reaction Catal. Lett. 146499

56. Yusop R M, Unciti-Broceta A and Bradley M 2012 A highly sensitive fluorescent viscosity sensor Bioorg. Med. Chem. Lett. 225780

57. Lamblin M, Nassar-Hardy L, Hierso J-C, Fouquet E and Felpin F-X 2010 Recyclable heterogeneous palladium catalysts in pure water: Sustainable developments in Suzuki, Heck, Sonogashira and Tsuji-Trost Reactions Adv. Synth. Catal. 35233

58. Jabbari A, Tahmasbi B, Nikoorazm M and GhorbaniChoghamarani A 2018 A new Pd-Schiff-base complex on boehmite nanoparticles: Its application in Suzuki reaction and synthesis of tetrazoles Appl. Organomet. Chem. 32 e4295

59. Veisi H, Ghadermazi M and Naderi A 2016 Biguanidine-functionalized chitosan to immobilize palladium nanoparticles as a novel, efficient and recyclable heterogeneous nanocatalyst for Suzuki-Miyaura coupling reactions Appl. Organomet. Chem. 30341

60. Farzad E and Veisi $\mathrm{H} 2018 \mathrm{Fe}_{3} \mathrm{O}_{4} / \mathrm{SiO}_{2}$ nanoparticles coated with polydopamine as a novel magnetite reductant and stabilizer sorbent for palladium ions: Synthetic application of $\mathrm{Fe}_{3} \mathrm{O}_{4} / \mathrm{SiO}_{2} @ \mathrm{PDA} / \mathrm{Pd}$ for reduction of 4-nitrophenol and Suzuki reactions J. Ind. Eng. Chem. 60114
61. Krishna R, Fernandes D M, Ventura J, Freire C and Titus E 2016 Novel synthesis of highly catalytic active $\mathrm{Cu} @ \mathrm{Ni} / \mathrm{RGO}$ nanocomposite for efficient hydrogenation of 4-nitrophenol organic pollutant Int. J Hydrog. Energy 4111608

62. Abay A K, Chen X and Kuo D-H 2017 Highly efficient noble metal free copper nickel oxysulfide nanoparticles for catalytic reduction of 4-nitrophenol, methyl blue, and rhodamine-B organic pollutants New J. Chem. 41 5628

63. Zhou R, Yang X, Zhang P, Yang L, Liu C, Liu D and Gui J 2018 Insights into catalytic roles of noble-metalfree catalysts $\mathrm{Co}_{\mathrm{x}} \mathrm{S}_{\mathrm{y}}$ for reduction of 4-nitrophenol PCCP 2027730

64. Morrissey C and He H 2018 Silicene catalyzed reduction of nitrobenzene to aniline: A mechanistic study Chem. Phys. Lett. 695228

65. Rocha M, Fernandes C, Pereira C, Rebelo S L, Pereira M F and Freire C 2015 Gold-supported magnetically recyclable nanocatalysts: a sustainable solution for the reduction of 4-nitrophenol in water $R S C A d v$. 55131

66. Sun W, Lu X, Tong Y, Zhang Z, Lei J, Nie G and Wang C 2014 Fabrication of highly dispersed palladium/graphene oxide nanocomposites and their catalytic properties for efficient hydrogenation of p-nitrophenol and hydrogen generation Int. J. Hydrog. Energy 399080

67. Lv Z-S, Zhu X-Y, Meng H-B, Feng J-J and Wang A-J 2019 One-pot synthesis of highly branched Pt@Ag core-shell nanoparticles as a recyclable catalyst with dramatically boosting the catalytic performance for 4-nitrophenol reduction J. Colloid Interface Sci. 538 349

68. Barman B K and Nanda K K 2015 Rapid reduction of GO by hydrogen spill-over mechanism by in situ generated nanoparticles at room temperature and their catalytic performance towards 4-nitrophenol reduction and ethanol oxidation Appl. Catal. A 49145

69. Kohantorabi M and Gholami M R 2018 Fabrication of novel ternary $\mathrm{Au} / \mathrm{CeO}_{2} @ g-\mathrm{C}_{3} \mathrm{~N}_{4}$ nanocomposite: Kinetics and mechanism investigation of 4-nitrophenol reduction, and benzyl alcohol oxidation Appl. Phys. A 124441

70. Shi G-M, Li S-T, Shi F-N, Shi X-F, Lv S-H and Cheng X-B 2018 A facile strategy for synthesis of

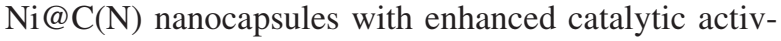
ity for 4-nitrophenol reduction Colloid. Surf. A 555170 